\title{
Analisis Ketahanan Gedung Apartemen Surabaya dengan Menggunakan Metode Respon Spektrum
}

\author{
(Performance Analysis of Surabaya Apartment Using Response Spectrum Method) \\ Iklil Afrida, Winda Tri Wahyuningtyas ${ }^{*}$, Krisnamurti \\ Jurusan Teknik Sipil, Fakultas Teknik, Universitas Jember \\ Jl. Kalimantan 37, Jember 68121 \\ ${ }^{*}$ Penulis Korespondensi E-mail: windatri.teknik@unej.ac.id
}

\begin{abstract}
Abstrak
Apartemen Surabaya merupakan bangunan 45 lantai yang di fungsikan sebagai apartemen dan mall dengan ketinggian total bangunan 138 m. Apartemen Surabaya terletak di Jalan Laguna Raya KJW Putih, Mulyorejo, Kota Surabaya, Jawa Timur dimana lokasi berdekatan dengan beberapa situs sesar aktif. Letak sesar aktif yaitu sesar aktif Lasem di sebelah utara dengan jarak $\pm 70 \mathrm{Km}$, sesar aktif Watu Kosek di sebelah selatan timur laut yang membujur dari Mojokerto hingga Madura dengan jarak $\pm 30 \mathrm{Km}$ dan sesar aktif Pasuruan di sebelah selatan yang membujur dari Pasuruan sampai Mojokerto dengan jarak $\pm 50 \mathrm{Km}$. Sehingga analisis ketahanan gempa diperlukan pada gedung apartemen untuk mengetahui ketahanan terhadap gempa. Analisis dinamik menggunakan metode respon spektrum digunakan untuk menganalisa gedung. Tujuan dari penelitian ini yaitu untuk mengetahui bagaimana cara mengevaluasi struktur dengan menggunakan analisis dinamik metode respon spektrum sesuai SNI 1726:2019. Hal yang ditinjau yaitu base shear, drift dan displacement pada gedung. Hasil analisa menunjukan displacement, drift, dan base shear memenuhi syarat yang telah ditentukan. Nilai drift terbesar arah X $0.22 \mathrm{~mm}$ pada lt 35 dan arah Y yaity $0.28 \mathrm{~mm}$ pada lt 23. Sedangkan untuk nilai displacement terbesar arah $\mathrm{X}$ dan $\mathrm{Y}$ yaitu $0.077 \mathrm{~m}$ dan $0.106 \mathrm{~m}$.
\end{abstract}

Kata Kunci: Ketahanan bangunan, analisis dinamik, respon spektrum, rasio simpangan antar lantai, displasemen, gaya geser dasar.

\section{Abstract}

Surabaya Apartment is a 45-storey building that functions as an apartment and mall with a total height $138 \mathrm{~m}$. Surabaya Apartment is located at Jalan Laguna Raya KJW Putih, Mulyorejo, Surabaya City, East Java where the location is adjacent to several active fault. The distance of active fault is : Lasem fault in the north $\pm 70 \mathrm{Km}$, Watu kosek fault in south east northeast $\pm 30 \mathrm{Km}$ and Pasuruan fault in the south $\pm 50 \mathrm{Km}$. Therefore earthquake analysis is needed to determine earthquake resistance. Dynamic analysis using response spectrum method is used to analyze this apartment. The aim of this research is to evaluated structure using response spectrum method based on SNI 1726:2019. This study evaluated base shear, drift and displacement on the apartment. The analysis results show that displacement, drift and base share fulfilled the requirements. Maximum value of drift in X direction is $0.22 \mathrm{~mm}$ on $35^{\text {th }}$ floor and $Y$ direction $0.28 \mathrm{~mm}$ on the $23^{\text {rd }}$ floor. And maximum value of displacement on $X$ and $Y$ direction is $0.077 \mathrm{~m}$ and $0.106 \mathrm{~m}$.

Keywords: Building vulnerability, dynamic analysis, response spectrum, drift ratio, displacement, base shear.

\section{PENDAHULUAN}

Gempa merupakan fenomena alam yang tidak dapat diprediksi besar dan waktu terjadinya. Ditinjau dari segi intensitasnya, gempa bervariasi dari gempa kecil, sedang, bahkan gempa besar. Terlepas daribesar kecilnya gempa, suatu struktur bangunan perlu dirancang dengan baik untuk menahan beban gempa yang bekerja padanya.[1].

Indonesia termasuk dalam ketegori negara dengan tingkat kerawanan gempa yang tinggi. Hal ini merupakan dampak dari kepulauan Indonesia yang terletak di tengah daerah cincin api pasifik, jalur sabuk alpide, pertemuan antar lempeng tektonik dan terdapat banyaknya gunung berapi aktif [2]. Oleh karena itu, kementerian pekerjaan umum dan perumahan rakyat pada tahun 2017 menerbitkan peta zona gempa di Indonesia [3] agar dapat digunakan untuk kebutuhan pembangunan dan kewaspadaan bagi masyarakat.

Untuk merancang bangunan tinggi, gempa bumi merupakan salah satu faktor yang sangat diperhitungkan, mengingat gempa akan mengakibatkan guncangan dan goyangan yang dapat merusak struktur bangunan [4]. Gempa adalah suatu bencana yang kerap kali terjadi yang dapat menyebabkan beberapa masalah kerusakan pada bangunan, karena dapat menyebabkan penurunan kekuatan dan kekakuan dari bangunana tersebut.

Gedung apartemen Surabaya adalah gedung bertingkat yang memiliki 45 lantai. Gedung apartemen Surabaya terdapat di wilayah Surabaya, Jawa Timur yang memiliki potensi gempa bumi dan kepadatan bangunan cukup tinggi. Oleh karena itu, perlu dilakukan anallisis kembali evaluasi ketahanan bangunan gedung apartemen Surabaya yang sesuai dengan SNI 1726:2019 dengan menggunakan analisis dinamik metode respon spectrum.

\section{METODE PENELITIAN}

Secara garis besat metode pelaksanaan penelitian terbagi menjadi dua tahap yaitu perhitungan respon spektrum dan tahap perhitungan respon gedung akibat 
gempa rencana. Pada tahap pertama dijelaskan secara detail sebagai berikut :

1. Detail bangunan : Bangunan apartemen, Surabaya, 45 lantai

2. Tanah dasar : Tanah sedang (Kelas D)

3. Kategori resiko bangunan : III $(\mathrm{Ie}=1,25)$

Tahap kedua yaitu permodelan struktur dengan menggunakan program bantu struktur. Permodelan menggunakan gambar detail yang didapatkan pada proyek apartemen.

Pemodelan 3D dilakukan dengan menggunakan aplikasi perangkat lunak analisis struktur, yang kemudian akan dianalisis guna mendapatkan drift, displacement dan base shear yang bekerja dalam struktur bangunan.

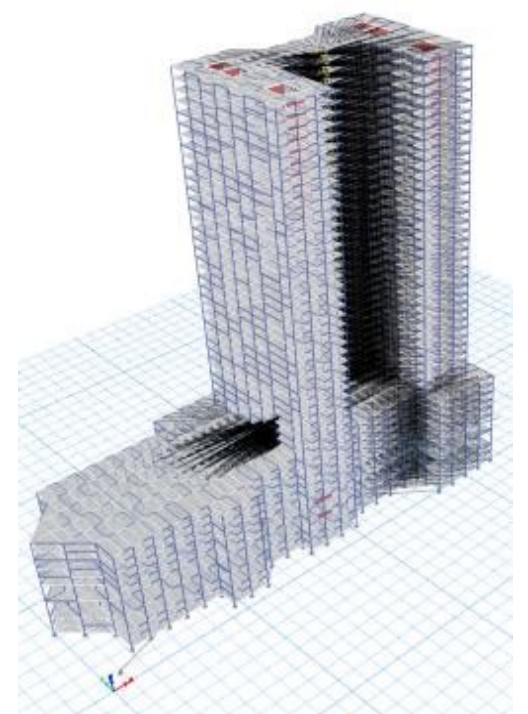

Gambar 1. Diagram Alir Pekerjaan Analisis Respon Spektrum.

\section{HASIL DAN PEMBAHASAN}

\section{Data Spesifikasi Bangunan}

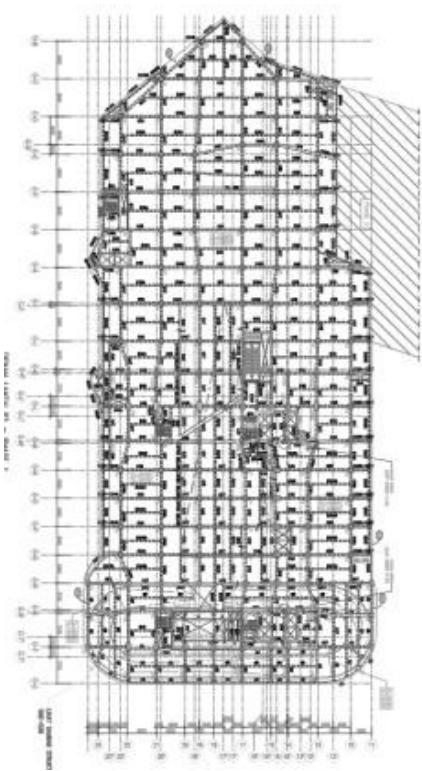

Gambar 2. Denah Apartemen Lantai 1-9.

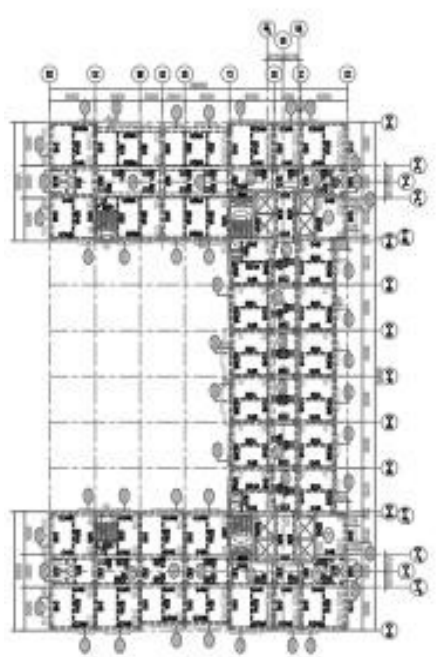

Gambar 3. Denah Apartemen Lantai 10 - rooftop.

Tabel 1. Data Elemen Struktur

\begin{tabular}{cc}
\hline Tipe & Tebal (cm) \\
\hline Pelat basemen & 15 \\
Pelat tipikal & 15 \\
Banlok induk & $40 / 80$ \\
Balok anak & $30 / 60$ \\
Kolom 1 & $20 / 20$ \\
Kolom 2 & $60 / 60$ \\
Kolom 3 & $100 / 100$ \\
\hline
\end{tabular}

Tabel 2. Material Bangunan

\begin{tabular}{lcc}
\hline \multirow{2}{*}{\multicolumn{1}{c}{ Fungsi }} & \multicolumn{2}{c}{ Mutu Beton } \\
\cline { 2 - 3 } & f'c & Ec \\
\cline { 2 - 3 } & Mpa & Mpa \\
\hline Balok & 40 & 29725,4 \\
Balok anak & 40 & 29725,4 \\
Balok induk & & \\
Kolom & 45 & 31528,6 \\
Kolom struktur & & \\
Wall & 40 & 29725,4 \\
Shearwall & & \\
Pelat & 35 & 27805,6 \\
Pelat atap & 35 & 27805,6 \\
Pelat lantai & & 27805,6 \\
Pelat basemen & 35 & 27805,6 \\
Ground slab & 35 & 25742,9 \\
Pondasi & & \\
Pondasi borpile & 30 &
\end{tabular}

Pemodelan 3D Menggunakan Program Bantu Struktur

Pemodelan 3D dilakukan dengan menggunakan aplikasi bantu yaitu struktur, yang kemudian akan dianalisis guna mendapatkan drift, displacement dan base shear yang bekerja dalam struktur bangunan. 
Validasi permodelan dihitung untuk mengontrol permodelan bangunan.

Beban perhitungan manual

: $83257835.51 \mathrm{~kg}$

Total beban dengan program : $85098810.86 \mathrm{~kg}$

\section{Validasi Pembebanan}

$$
\begin{aligned}
= & \frac{(\text { Perhitungan beban rencana }- \text { Beban Etabs })}{\text { Perhitungan beban rencana }} \\
= & \frac{(83257835.51-85098810.86)}{83257835.51}=0,0216=2,16 \%
\end{aligned}
$$

Validasi menunjukan $2.16 \%<10 \%$ sehingga permodelan dapat digunakan dan dilanjutkan untuk perhitungan.

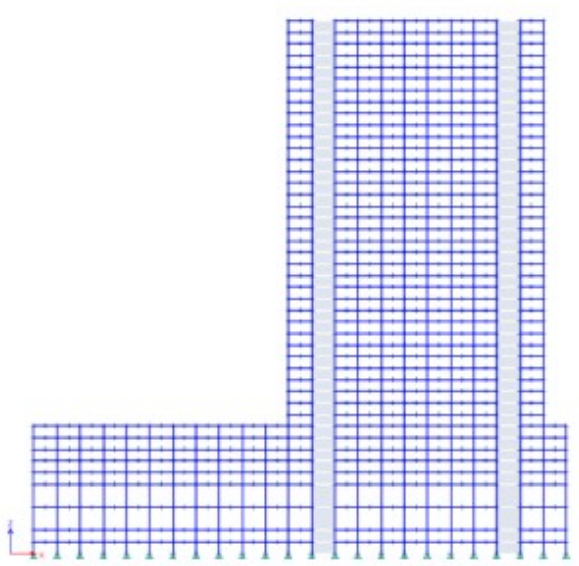

Gambar 4. Permodelan Struktur

\section{Faktor Reduksi Gempa}

Faktor reduksi gempa diambil dari tabel nilai $\mathrm{R}, \Omega_{0}$ dan $\mathrm{Cd}$ SNI 1726:2019, nilai faktor reduksi gempa dengan jenis sistem rangka penahan momen dengan rangka momen beton bertulang khusus adalah 8 .

\section{Grafik Respon Spektrum}

Tanah dasar termasuk dalam kategori tanah sedang (kelas D)

Kategori resiko bangunan : III $(\mathrm{Ie}=1,25)$

Fungsi bangunan : Apartemen

Tebal plat basement

: $150 \mathrm{~mm}$

Tebal plat lantai

: $150 \mathrm{~mm}$

Tebal plat atap

Tebal shearwall lift

: $150 \mathrm{~mm}$

: $250 \mathrm{~mm}$

Tebal Corewall

: $4500 \mathrm{~mm}$

Jumlah lantai

Nilai Ss

: 45 lantai

Nilai Si

: $0,8 \mathrm{~g}$

: $0,3 \mathrm{~g}$

Nilai Fa

$: 1,18$

Nilai Fy

$: 2$

Nilai $\mathrm{S}_{\mathrm{DS}}: 2 / 3 \times \mathrm{Fa} \times \mathrm{Ss}$

: 0,62933

Nilai $\mathrm{S}_{\mathrm{DI}}: 2 / 3$ x Fy x Si

: 0,4

Nilai $\mathrm{T}_{0}: 0,2\left(\mathrm{~S}_{\mathrm{DI}} / \mathrm{S}_{\mathrm{DS}}\right)$

: $0,1271 \mathrm{~s}$

Nilai Ts: $\left(\mathrm{S}_{\mathrm{DI}} / \mathrm{S}_{\mathrm{DS}}\right)$

$\mathrm{T}_{\mathrm{L}}$

: $0,635593 \mathrm{~s}$

: $16 \mathrm{~s}$

$: 2,4 \mathrm{~s}$

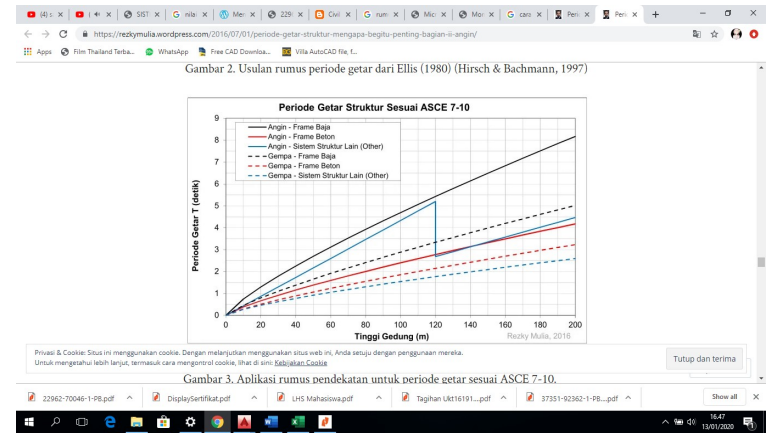

Gambar 5. Penenentuan Nilai Periode Getar T Sesuai ASCE 7-10.

Sehingga didapat grafik respons spektrum sebagai berikut :

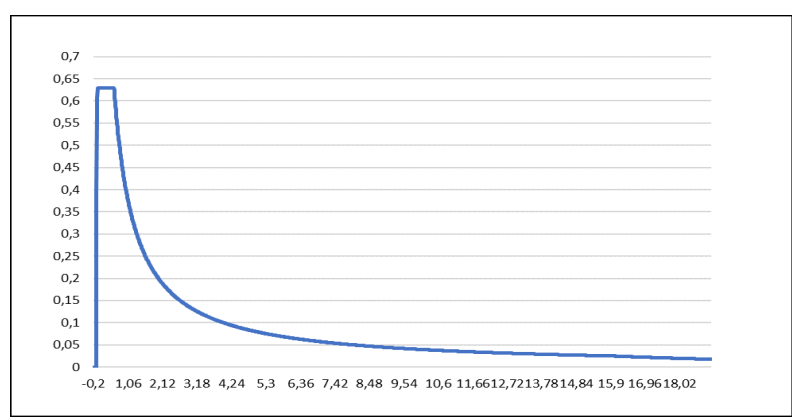

Gambar 6. Grafik Respon Spektrum.

\section{Hasil Pemodelan Etabs}

1. Displacement

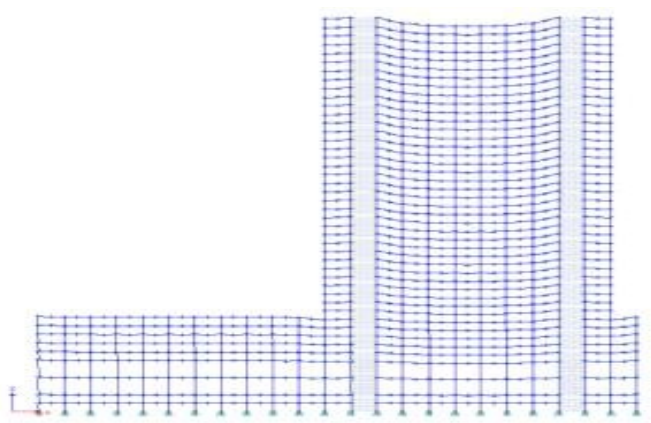

Gambar 8. Displacements (0,9 D - 1 EQx - 0,3 EQy) (mm)

2. Plane Shear Diagram

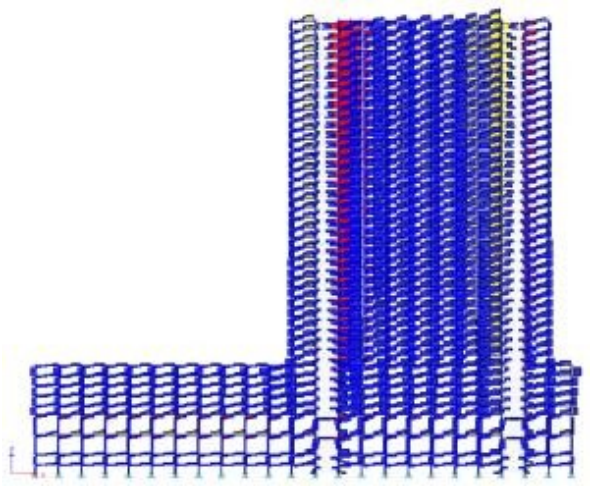

Gambar 9. In-plane shear diagram (0,9 D - 1 EQx - 0,3 EQy) $(\mathrm{kN})$ 


\section{Plane Moment Diagram}

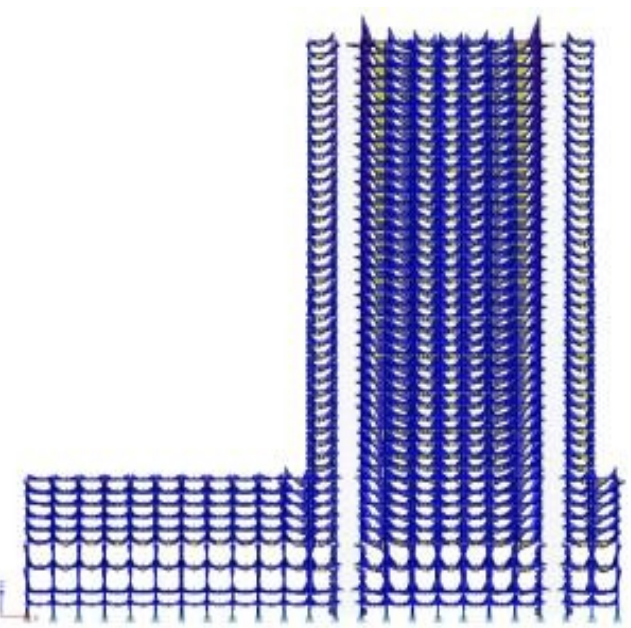

Gambar 10. In-plane momen diagram (0,9 D - 1 EQx - 0,3 EQy) (kN-m)

4. Shear Force

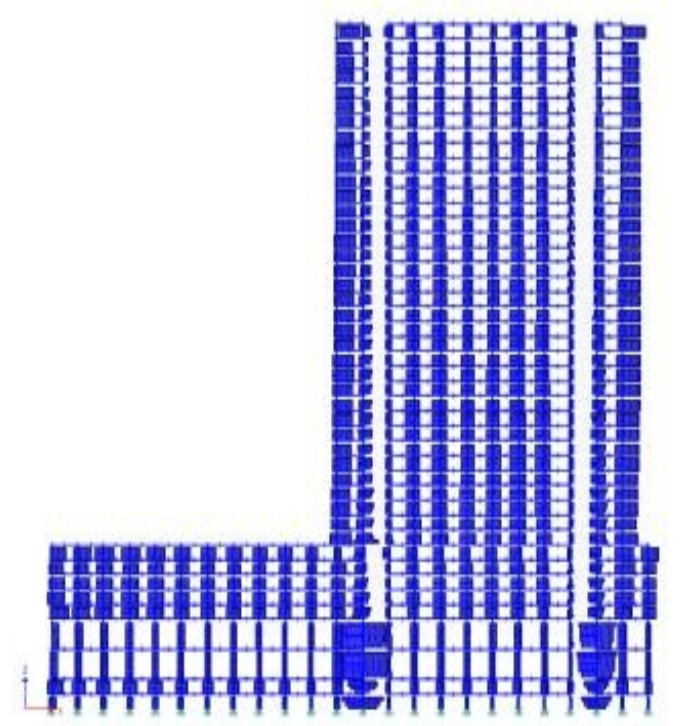

Gambar 11. Shear force (0,9 D - 1 EQx - 0,3 EQy) (kN)

Analisi Drift Rasio, Displacement, dan Base Shear

\section{Displacement}

Menurut SNI 1726:2019 batasan displacement untuk kategori resiki III yaitu $\frac{0,015 x h s x}{\rho}$. Maka displacement yang diijinkan pada lantai $35 \frac{0,015 \times 136}{1,3}$ $=1.569230769 \mathrm{~m}$.

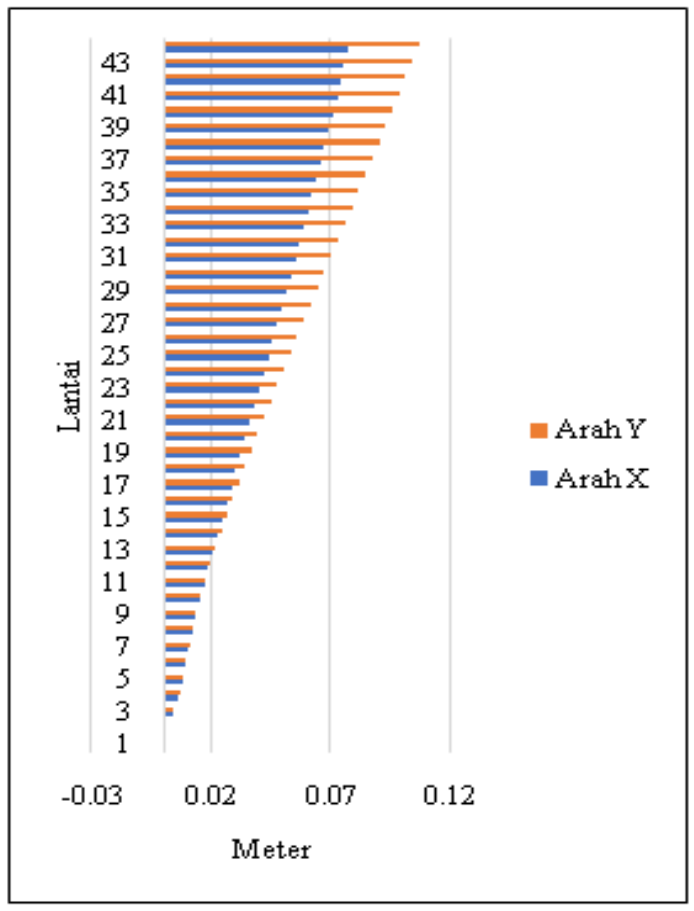

Gambar 12. Grafik Displacement Maksimum Tiap Lantai Arah X dan Y.

2. Drift

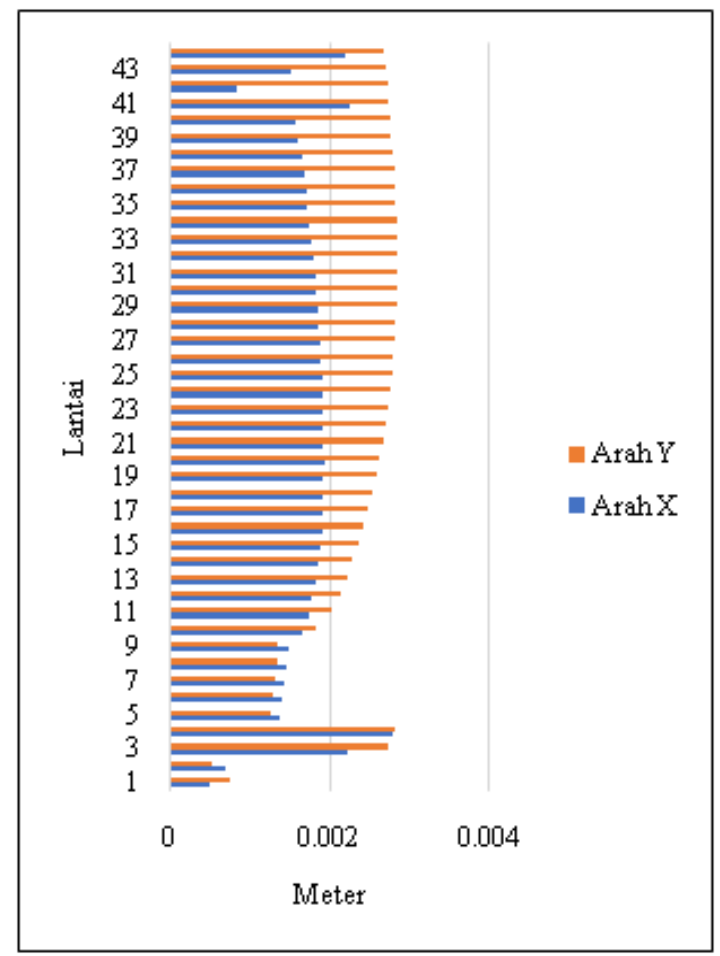

Gambar 13. Grafik Drift Maksimum Tiap Lantai Arah X dan Y. 
3. Base Shear

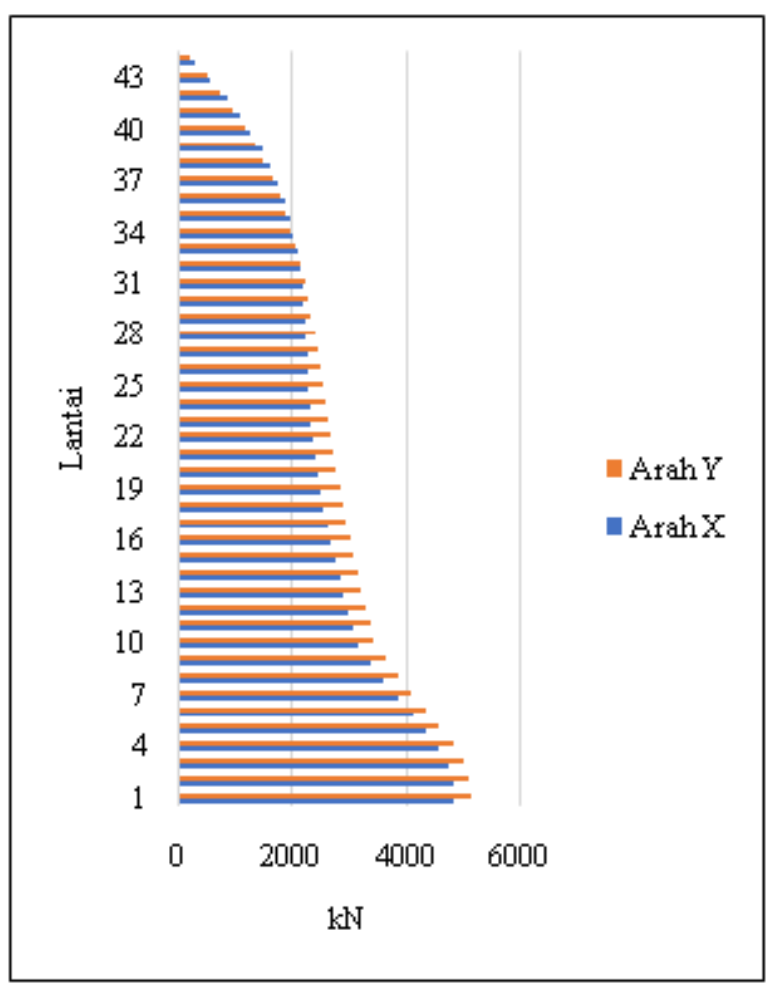

Gambar 14. Grafik Base Shear Maksimum Tiap Lantai Arah X dan Y.

Nilai displacement, drift dan base share yang telah didapatkan digunakan untuk menghitung batas layan struktur untuk mengetahui kinerja gedung akibat beban gempa [5]. Persyaratan batas layan struktur, dihitung dari simpangan antar tingkat dari struktur gedung dimana tidak boleh melampaui 0,03/R x tinggi tigkat atau $30 \mathrm{~mm}$ untuk arah $\mathrm{X}$ dan arah Y [6].

Tabel 3. Kontrol Kinerja Batas Layan Gedung Arah X

\begin{tabular}{ccccc}
\hline Lantai & $\begin{array}{c}\Delta \text { s arah X } \\
(\mathbf{m})\end{array}$ & $\begin{array}{c}\text { As antar } \\
\text { tingkat } \mathbf{~} \\
(\mathbf{m})\end{array}$ & $\begin{array}{c}\text { Syarat } \\
(\mathbf{0 . 0 3} / \mathbf{R}) * \mathbf{H}\end{array}$ & Ket. \\
\hline A 35 & 0.07723 & 0.00222 & 0.01125 & oke \\
A 34 & 0.07501 & 0.00153 & 0.01125 & oke \\
A 33 & 0.07348 & 0.00084 & 0.01125 & oke \\
A 32 & 0.07264 & 0.00228 & 0.01125 & oke \\
A 31 & 0.07036 & 0.0016 & 0.01125 & oke \\
A 30 & 0.06876 & 0.00163 & 0.01125 & oke \\
A 29 & 0.06713 & 0.00166 & 0.01125 & oke \\
A 28 & 0.06547 & 0.0017 & 0.01125 & oke \\
A 27 & 0.06377 & 0.00172 & 0.01125 & oke \\
A 26 & 0.06205 & 0.00174 & 0.01125 & oke \\
A 25 & 0.06031 & 0.00177 & 0.01125 & oke \\
A 24 & 0.05854 & 0.0018 & 0.01125 & oke \\
A 23 & 0.05674 & 0.00181 & 0.01125 & oke \\
A 22 & 0.05493 & 0.00184 & 0.01125 & oke \\
\hline
\end{tabular}

\begin{tabular}{|c|c|c|c|c|}
\hline Lantai & $\begin{array}{c}\Delta s \underset{(\mathbf{m})}{\operatorname{arah} X} \\
\quad\end{array}$ & $\begin{array}{c}\text { As antar } \\
\text { tingkat } X \\
\text { (m) }\end{array}$ & $\begin{array}{c}\text { Syarat } \\
(0.03 / R)^{*} H\end{array}$ & Ket. \\
\hline A 21 & 0.05309 & 0.00185 & 0.01125 & oke \\
\hline A 20 & 0.05124 & 0.00187 & 0.01125 & oke \\
\hline A 19 & 0.04937 & 0.00188 & 0.01125 & oke \\
\hline A 18 & 0.04749 & 0.0019 & 0.01125 & oke \\
\hline A 17 & 0.04559 & 0.0019 & 0.01125 & oke \\
\hline A 16 & 0.04369 & 0.00192 & 0.01125 & oke \\
\hline A 15 & 0.04177 & 0.00192 & 0.01125 & oke \\
\hline A 14 & 0.03985 & 0.00194 & 0.01125 & oke \\
\hline A 13 & 0.03791 & 0.00193 & 0.01125 & oke \\
\hline A 12 & 0.03598 & 0.00194 & 0.01125 & oke \\
\hline A 11 & 0.03404 & 0.00195 & 0.01125 & oke \\
\hline A 10 & 0.03209 & 0.00194 & 0.01125 & oke \\
\hline A 9 & 0.03015 & 0.00193 & 0.01125 & oke \\
\hline A 8 & 0.02822 & 0.00193 & 0.01125 & oke \\
\hline A 7 & 0.02629 & 0.00192 & 0.01125 & oke \\
\hline A 6 & 0.02437 & 0.0019 & 0.01125 & oke \\
\hline A 5 & 0.02247 & 0.00187 & 0.01125 & oke \\
\hline A 4 & 0.0206 & 0.00185 & 0.01125 & oke \\
\hline A 3 & 0.01875 & 0.0018 & 0.01125 & oke \\
\hline A 2 & 0.01695 & 0.00176 & 0.01875 & oke \\
\hline A 1 & 0.01519 & 0.00167 & 0.01875 & oke \\
\hline P5 & 0.01352 & 0.00151 & 0.01125 & oke \\
\hline $\mathrm{P} 4$ & 0.01201 & 0.00148 & 0.01125 & oke \\
\hline P3 & 0.01053 & 0.00146 & 0.01125 & oke \\
\hline $\mathrm{P} 2$ & 0.00907 & 0.00143 & 0.01125 & oke \\
\hline $\mathrm{P} 1$ & 0.00764 & 0.00139 & 0.01125 & oke \\
\hline Mall 2 & 0.00625 & 0.0028 & 0.01125 & oke \\
\hline Mall 1 & 0.00345 & 0.00224 & 0.01125 & oke \\
\hline B 2 & 0.00121 & 0.00071 & 0.01125 & oke \\
\hline B 1 & 0.0005 & 0.0005 & 0.01125 & oke \\
\hline
\end{tabular}

Tabel 4. Kontrol Kinerja Batas Layan Gedung Arah Y

\begin{tabular}{ccccc}
\hline Lantai & $\begin{array}{c}\Delta \text { s arah Y } \\
(\mathbf{m})\end{array}$ & $\begin{array}{c}\text { As antar } \\
\text { tingkat Y } \\
(\mathbf{m})\end{array}$ & $\begin{array}{c}\text { Syarat } \\
(\mathbf{0 . 0 3} / \mathbf{R}) * \mathbf{H}\end{array}$ & Ket. \\
\hline A 35 & 0.10648 & 0.00269 & 0.01125 & oke \\
A 34 & 0.10379 & 0.00271 & 0.01125 & oke \\
A 33 & 0.10108 & 0.00274 & 0.01125 & oke \\
A 32 & 0.09834 & 0.00275 & 0.01125 & oke \\
A 31 & 0.09559 & 0.00278 & 0.01125 & oke \\
A 30 & 0.09281 & 0.00279 & 0.01125 & oke \\
A 29 & 0.09002 & 0.00281 & 0.01125 & oke \\
A 28 & 0.08721 & 0.00283 & 0.01125 & oke \\
A 27 & 0.08438 & 0.00284 & 0.01125 & oke \\
A 26 & 0.08154 & 0.00285 & 0.01125 & oke \\
\hline
\end{tabular}




\begin{tabular}{|c|c|c|c|c|}
\hline Lantai & $\underset{(\mathbf{m})}{\Delta \mathbf{a r a h} Y}$ & $\begin{array}{l}\text { As antar } \\
\text { tingkat } Y \\
\text { (m) }\end{array}$ & $\begin{array}{c}\text { Syarat } \\
(0.03 / R) * H\end{array}$ & Ket. \\
\hline A 25 & 0.07869 & 0.00286 & 0.01125 & oke \\
\hline A 24 & 0.07583 & 0.00286 & 0.01125 & oke \\
\hline A 23 & 0.07297 & 0.00287 & 0.01125 & oke \\
\hline A 22 & 0.0701 & 0.00287 & 0.01125 & oke \\
\hline A 21 & 0.06723 & 0.00287 & 0.01125 & oke \\
\hline A 20 & 0.06436 & 0.00286 & 0.01125 & oke \\
\hline A 19 & 0.0615 & 0.00285 & 0.01125 & oke \\
\hline A 18 & 0.05865 & 0.00284 & 0.01125 & oke \\
\hline A 17 & 0.05581 & 0.00282 & 0.01125 & oke \\
\hline A 16 & 0.05299 & 0.00281 & 0.01125 & oke \\
\hline A 15 & 0.05018 & 0.00278 & 0.01125 & oke \\
\hline A 14 & 0.0474 & 0.00275 & 0.01125 & oke \\
\hline A 13 & 0.04465 & 0.00272 & 0.01125 & oke \\
\hline A 12 & 0.04193 & 0.00269 & 0.01125 & oke \\
\hline A 11 & 0.03924 & 0.00265 & 0.01125 & oke \\
\hline A 10 & 0.03659 & 0.00261 & 0.01125 & oke \\
\hline A 9 & 0.03398 & 0.00255 & 0.01125 & oke \\
\hline A 8 & 0.03143 & 0.00251 & 0.01125 & oke \\
\hline A 7 & 0.02892 & 0.00244 & 0.01125 & oke \\
\hline A 6 & 0.02648 & 0.00239 & 0.01125 & oke \\
\hline A 5 & 0.02409 & 0.00231 & 0.01125 & oke \\
\hline A 4 & 0.02178 & 0.00223 & 0.01125 & oke \\
\hline A 3 & 0.01955 & 0.00215 & 0.01125 & oke \\
\hline A 2 & 0.0174 & 0.00205 & 0.01875 & oke \\
\hline A 1 & 0.01535 & 0.00184 & 0.01875 & oke \\
\hline P5 & 0.01351 & 0.00137 & 0.01125 & oke \\
\hline $\mathrm{P} 4$ & 0.01214 & 0.00135 & 0.01125 & oke \\
\hline P3 & 0.01079 & 0.00132 & 0.01125 & oke \\
\hline $\mathrm{P} 2$ & 0.00947 & 0.0013 & 0.01125 & oke \\
\hline P1 & 0.00817 & 0.00128 & 0.01125 & oke \\
\hline Mall 2 & 0.00689 & 0.00284 & 0.01125 & oke \\
\hline Mall 1 & 0.00405 & 0.00275 & 0.01125 & oke \\
\hline B 2 & 0.0013 & 0.00053 & 0.01125 & oke \\
\hline B 1 & 0.00077 & 0.00077 & 0.01125 & oke \\
\hline
\end{tabular}

Tabel 3 dan Tabel 4 Menunjukan bahwa kinerja batas layan gedung arah $\mathrm{X}$ dan arah $\mathrm{Y}$ telah memenuhi syarat batas layan gedung. Dimana nilai simpangan antar tingkat arah $X$ dan arah $Y<0,03 R$ dengan SNI 1726:2019 [6].

Hal lain yang perlu diperhitungkan yaitu kinerja batas utimit gedung, dalam segala hal simpangan antar lantai yang dihitung dari simpangan struktur $(\Delta \mathrm{m} \mathrm{x} \xi)$ tidak boleh melampaui 0,02 kali tinggi tingkat yang bersangkutan [7].

$\Delta \mathrm{s}$ atar tingkat $=\Delta$ s Apartement $35-\Delta$ s Apartement 34 $=0,07723-0,07501=0,00222 \mathrm{~m}$

$\xi \mathrm{x} \Delta \mathrm{s}$ atar tingkat $\quad<\quad 0,02 \times \mathrm{H}$
$5,6 \times 0,00222$

0,012432

$<\quad 0,02 \times 3$

$<\quad 0,06 \ldots . . .$. (memenuhi)

Tabel 5. Kontrol Kinerja Batas Ultimit

\begin{tabular}{|c|c|c|c|c|}
\hline Lantai & $\begin{array}{l}\text { G.Am Antar } \\
\text { Tingkat X }\end{array}$ & $\begin{array}{l}\text { F.Am Antar } \\
\text { Tingkat Y }\end{array}$ & $\begin{array}{c}\text { Syarat } \\
\text { Am }\end{array}$ & Ket. \\
\hline A 35 & 0.012432 & 0.015064 & 0.06 & oke \\
\hline A 34 & 0.008568 & 0.015176 & 0.06 & oke \\
\hline A 33 & 0.004704 & 0.015344 & 0.06 & oke \\
\hline
\end{tabular}

0.015568

0.06

oke

A $30 \quad 0.009128$

0.015624

0.06

oke

A $29 \quad 0.009296$

0.015736

0.06

A $28 \quad 0.00952$

0.015848

A 27

0.009632

0.015904

0.06

0.06

oke

A 26

0.009744

0.01596

0.06

A 25

0.009912

0.016016

A 24

0.01008

0.016016

0.06

0.06

A 23

0.010136

0.016072

0.06

A $22 \quad 0.010304$

0.016072

A 21

0.01036

0.016072

0.06

0.06

A 20

0.010472

0.016016

0.06

0.06

0.06

A $18 \quad 0.01064$

0.015904

A 17

0.01064

0.015792

A 16

0.010752

0.015736

0.06

0.06

0.06

A $15 \quad 0.010752$

0.015568

0.0154

A $13 \quad 0.010808 \quad 0.015232$

0.06

0.06

0.06

0.06

A $11 \quad 0.01092$

0.015064

0.01484

A $10 \quad 0.010864$

0.014616

0.06

A 9

0.010808

0.01428

0.06

0.06

0.06

A $7 \quad 0.010752$

0.014056

0.013664

A $6 \quad 0.01064$

0.013384

0.06

0.06

0.06

A $4 \quad 0.01036$

0.012936

0.06

A $3 \quad 0.01008$

0.01204

A

A

0.009856

0.01148

0.06

0.06

0.06

0.06

0.06

0.06

0.06

0.1

oke

oke

oke

oke

oke

oke

oke

oke

oke

oke

oke

oke

oke

oke

oke

oke

oke

oke

oke

oke

oke

oke

oke

oke

oke

oke

oke

oke

oke

oke

P3 0.008176

0.007392

oke

$\begin{array}{lll}\mathrm{P} 2 & 0.008008 & 0.00728\end{array}$

oke

P1 0.007784

0.007168

oke

Mall 2

0.01568

0.015904

oke 


\begin{tabular}{|c|c|c|c|c|}
\hline Lantai & $\begin{array}{c}\text { G.Am Antar } \\
\text { Tingkat X }\end{array}$ & $\begin{array}{c}\xi . A m \text { Antar } \\
\text { Tingkat Y }\end{array}$ & $\begin{array}{c}\text { Syarat } \\
\text { Am }\end{array}$ & Ket. \\
\hline Mall 1 & 0.012544 & 0.0154 & 0.1 & oke \\
\hline B 2 & 0.003976 & 0.002968 & 0.06 & oke \\
\hline B 1 & 0.0028 & 0.004312 & 0.06 & oke \\
\hline
\end{tabular}

Hasil perhitungan batas ultimate arah X dan arah Y pada table 5 menunjukan bahwa struktur masih memenuhi batas ultimate kinerja gedung.

Tabel 6. Kontrol Displacement Maksimum Analisis Respon Spektrum.

\begin{tabular}{ccccc}
\hline Lantai & $\begin{array}{c}\text { Ux respon } \\
\text { spektrum }\end{array}$ & $\begin{array}{c}\text { Uy respon } \\
\text { spektrum }\end{array}$ & $\begin{array}{c}\text { Syarat } \\
(\mathbf{0 , 0 1 5 h x ) / p}\end{array}$ & Ket. \\
\hline A 35 & 0.07723 & 0.10648 & 1.5692308 & oke \\
A 34 & 0.07501 & 0.10379 & 1.5346154 & oke \\
A 33 & 0.07348 & 0.10108 & 1.5 & oke \\
A 32 & 0.07264 & 0.09834 & 1.4653846 & oke \\
A 31 & 0.07036 & 0.09559 & 1.4307692 & oke \\
A 30 & 0.06876 & 0.09281 & 1.3961538 & oke \\
A 29 & 0.06713 & 0.09002 & 1.3615385 & oke \\
A 28 & 0.06547 & 0.08721 & 1.3269231 & oke \\
A 27 & 0.06377 & 0.08438 & 1.2923077 & oke \\
A 26 & 0.06205 & 0.08154 & 1.2576923 & oke \\
A 25 & 0.06031 & 0.07869 & 1.2230769 & oke \\
A 24 & 0.05854 & 0.07583 & 1.1884615 & oke \\
A 23 & 0.05674 & 0.07297 & 1.1538461 & oke \\
A 22 & 0.05493 & 0.0701 & 1.1192308 & oke \\
A 21 & 0.05309 & 0.06723 & 1.0846154 & oke \\
A 20 & 0.05124 & 0.06436 & 1.05 & oke \\
A 19 & 0.04937 & 0.0615 & 1.0153846 & oke \\
A 18 & 0.04749 & 0.05865 & 0.9807692 & oke \\
A 17 & 0.04559 & 0.05581 & 0.9461538 & oke \\
A 16 & 0.04369 & 0.05299 & 0.9115385 & oke \\
A 15 & 0.04177 & 0.05018 & 0.8769231 & oke \\
A 14 & 0.03985 & 0.0474 & 0.8423077 & oke \\
A 13 & 0.03791 & 0.04465 & 0.8076923 & oke \\
A 12 & 0.03598 & 0.04193 & 0.7730769 & oke \\
A 11 & 0.03404 & 0.03924 & 0.7384615 & oke \\
A 10 & 0.03209 & 0.03659 & 0.7038461 & oke \\
A 9 & 0.03015 & 0.03398 & 0.6692308 & oke \\
A 8 & 0.02822 & 0.03143 & 0.6346154 & oke \\
A 7 & 0.02629 & 0.02892 & 0.6 & oke \\
A 6 & 0.02437 & 0.02648 & 0.5653846 & oke \\
A 5 & 0.02247 & 0.02409 & 0.5307692 & oke \\
A 4 & 0.0206 & 0.02178 & 0.4961538 & oke \\
A 3 & 0.01875 & 0.01955 & 0.4615385 & oke \\
A 2 & 0.01695 & 0.0174 & 0.4269231 & oke
\end{tabular}

\begin{tabular}{ccccc}
\hline Lantai & $\begin{array}{c}\text { Ux respon } \\
\text { spektrum }\end{array}$ & $\begin{array}{c}\text { Uy respon } \\
\text { spektrum }\end{array}$ & $\begin{array}{c}\text { Syarat } \\
(\mathbf{0 , 0 1 5 h x )} / \mathbf{\rho}\end{array}$ & Ket. \\
\hline A 1 & 0.01519 & 0.01535 & 0.3923077 & oke \\
P5 & 0.01352 & 0.01351 & 0.3576923 & oke \\
P4 & 0.01201 & 0.01214 & 0.3230769 & oke \\
P3 & 0.01053 & 0.01079 & 0.2884615 & oke \\
P2 & 0.00907 & 0.00947 & 0.2538461 & oke \\
P1 & 0.00764 & 0.00817 & 0.2192308 & oke \\
Mall 2 & 0.00625 & 0.00689 & 0.1846154 & oke \\
Mall 1 & 0.00345 & 0.00405 & 0.1269231 & oke \\
B 2 & 0.00121 & 0.0013 & 0.0692308 & oke \\
B 1 & 0.0005 & 0.00077 & 0.0346154 & oke \\
\hline
\end{tabular}

Nilai displacement maksimum yang diijinkan pada gedung yaitu $1.56 \mathrm{~m}$. Hasil running program bantu displacement yang terjadi tertinggi yaitu pada lantai A35 sebesar $0.077 \mathrm{~m}$ arah ux dan $0.106 \mathrm{~m}$ arah uy. Kontrol displacement pada seluruh gedung sudah memenuhi batas kinerja gedung.

\section{KESIMPULAN}

Setelah dilakukan analisi dinamik menggunakan metode respon spektrum maka dapat diambil kesimpulan bahwa simpangan antar lantai (Drift) arah $\mathrm{X}$ dan $\mathrm{Y}$ dinyatakan aman terhadap kinerja batas layan $(0.03 / \mathrm{R})^{*} \mathrm{H}$ dan batas ultimit $\xi . \Delta \mathrm{m}$ dan hasil dari displasement maksismum arah $\mathrm{X}$ didapat $0,07723 \mathrm{~m}$ dan arah $\mathrm{Y}$ didapat $0,10648 \mathrm{~m}$ sehingga dapat dinyatakan telah memenuhi syarat batas maksimum $\left[\left(0,015 \mathrm{~h}_{\mathrm{sx}}\right) / \rho\right]=1.57 \mathrm{~m}$.

Hasil simpangan atar latai (Drift) terbesar arah $\mathrm{X}$ didapat $0,22 \mathrm{~mm}$ pada latai Apartemen 35 dan arah $\mathrm{Y}$ didapat $0,29 \mathrm{~mm}$ pada latai Apartemen 23 sedangkan hasil base shear terberat arah X didapat $4871,12 \mathrm{kN}$ pada lantai Basement 1 dan arah $\mathrm{Y}$ didapat 5160,36 pada lantai Basement 1.

Dari kesimpulan diatas dapat diketahui bahwa displacement, drift, dan base shear memenuhi syarat batas layan dan batas ultimit yang telah ditentukan, oleh karena itu struktur bangunan gedung apartement east coast mansion surabaya dinilai layak.

\section{SARAN}

Adapun beberapa saran apabila dimasa yang akan datang dilakukan penelitian lanjutan adalah analisis respon spektrum perlu dicoba pada gedung-gedung tinggi lainya untuk mendalami perilaku seismik gedung bertingkat banyak.

\section{DAFTAR PUSTAKA}

[1] R. Kurniawan, D. Nurtanto, and G. A. Hayu, "COMPARATIVE STUDY OF THE BEHAVIOUR OF BUILDING STRUCTURE OF HOTEL DAFAM LOTUS JEMBER BY USING MOMENT RESISTING FRAME AND ECCENTRICALLY BRACED FRAME," J. Rekayasa Sipil dan Lingkung., 2018, doi: 10.19184/jrsl.v2i01.7435. 
[2] Tim Pemutakhiran Peta Bahaya Gempa Bumi Indonesia, Peta Sumber dan Bahaya Gempa Indonesia. 2017.

[3] Kemen PUPR, peta zona gempa. 2017.

[4] A. M. Reinhorn, "The UB-NEES Versatile High Performance Testing Facility," 13th WCEE, 2004.

[5] G. Negro, P., Pinto, A. V., Verzeletti, G. and Magonette, "No PsD Test on a Four Storey R/C
Building Designed Ac-cording to Erocodes," J. Struct. Eng., 1996.

[6] SNI 1726:2019, Tata Cara Perencanaan Ketahanan Gempa untuk Struktur Bangunan Gedung dan Non Gedung. 2019.

[7] CASCADE6, Directory of European Facilities for Seismic and Dy-namic Tests in Support of Industry, LNEC (Lisbon). 2005. 